\title{
Prevalence and factors associated with utilization of rehabilitation services among people with physical disabilities in Kampala, Uganda. A descriptive cross sectional study
}

Swaibu Zziwa 1* (D, Harriet Babikako², Doris Kwesiga ${ }^{3}$, Olive Kobusingye', Jacob A. Bentley ${ }^{4}$, Frederick Oporia', Rebecca Nuwematsiko ${ }^{1}$, Abdulgafoor Bachani ${ }^{4}$, Lynn M. Atuyambe ${ }^{1}$ and Nino Paichadze ${ }^{5}$

\begin{abstract}
Background: Worldwide, fifteen percent (15\%) of the world's population or one (1) billion people live with some form of disability. In Uganda, 12.4\% of the Uganda's population lives with some form of disability and Kawempe division accounts for (22.6\%) of all persons with disabilities living in Kampala district. Rehabilitation services are provided within Kawempe division at Mulago hospital physiotherapy department and Katalemwa rehabilitation center in Kampala district, Uganda at a free and a subsidized cost to help to improve the function, independence, and quality of life of persons with physical disabilities. However, many people with physical disabilities do not utilize the services and the reasons are not clear.

Methods: The study design was a descriptive cross-sectional study employing quantitative methods of data collection. A total of 318 participants were included in the study. Simple random sampling was used to select the study participants. Ethical issues were maintained at all levels during data collection and dissemination of results.

Results: The study revealed a prevalence of $26.4 \%$ of the utilization rehabilitation services among people with physical disabilities in Kawempe division, Kampala, Uganda. Factors that were significantly associated with utilization of rehabilitation services among people with physical disabilities at multivariable logistic regression analysis included; age (AOR: 0.30; 95\% Cl: 0.12-0.74), socioeconomic status (AOR: 2.13; 95\% Cl: 1.03-4.41), education level (AOR: $4.3 ; 95 \% \mathrm{Cl}: 1.34-13.91$ ) and awareness of the participants about the rehabilitation services (AOR: $5.1 ; 95 \% \mathrm{Cl}$ : 2.74-9.54) at $p$ value $\leq 0.05$.

Conclusion: The study revealed a prevalence of $26.4 \%$ of the utilization rehabilitation services among people with physical disabilities in Kawempe division, Uganda. Factors that were significantly associated with utilization of rehabilitation services included; age, socioeconomic status, education level and awareness of the participants about the services. Therefore, the government and other relevant stake holders should increase sensitization and awareness of rehabilitation services, their benefits and facilities providing such services to people with physical disabilities, healthcare professionals and the general public.
\end{abstract}

Keywords: People with physical disability, Rehabilitation services and Kawempe division

\footnotetext{
* Correspondence: ssziwas@gmail.com

${ }^{1}$ Department of Disease Control and Environmental Health, Makerere

University School of Public Health, College of Health Sciences, New Mulago

Hill Hospital Complex, P.O Box 7072, Kampala, Uganda

Full list of author information is available at the end of the article
}

(c) The Author(s). 2019 Open Access This article is distributed under the terms of the Creative Commons Attribution 4.0 International License (http://creativecommons.org/licenses/by/4.0/), which permits unrestricted use, distribution, and reproduction in any medium, provided you give appropriate credit to the original author(s) and the source, provide a link to the Creative Commons license, and indicate if changes were made. The Creative Commons Public Domain Dedication waiver (http://creativecommons.org/publicdomain/zero/1.0/) applies to the data made available in this article, unless otherwise stated. 


\section{Background}

International Classification of Functioning and disability (ICF) defines disability as a permanent impairment, activity limitation and restriction in participation in any life situation resulting from any health condition whether congenital or acquired [1,2]. A physical disability was defined as a permanent mobility, visual, speech and hearing impairment from any health condition whether congenital or acquired [1]. Rehabilitation is a set of interventions designed to optimize functioning and reduce disability in individuals with health conditions in interaction with their environment $[3,4]$. A Health condition refers to disease (acute or chronic), disorder, injury or trauma $[3,5]$. According to World Health Organization (WHO), rehabilitation is one of the essential components of the quality health services that should be included in Universal Health Coverage. This means that all individuals should be able to access quality rehabilitation services without fear of financial hardships $[6,7]$.

Worldwide, disability is a major public health concern. Globally, it is estimated that one billion people of the world's population (15\%) live with some form of disability [8].. About 110 to 190 million adults encounter substantial difficulties in their daily lives $[8,9]$. In order to reduce the number of person with disabilities (PWDs), the WHO Member States in 2014 endorsed global disability action plan 2014-2021 with the aim to remove barriers and improve access to health services; strengthen and extend rehabilitation and communitybased rehabilitation [8]. The plan was adopted in response to 66th World Health Assembly resolution on disability which urges member states to implement the recommendations of the United Nation's Convention of the Rights of PWDs (CRPD); work towards the inclusion of all PWDs in health care; promote rehabilitation services across the life course and for a range of different health conditions with the goal of attaining good health for all PWDs [10, 11].

Furthermore, the WHO Member States, international and professional organizations, non-governmental organizations and rehabilitation experts on 7th February 2017 issued Rehabilitation 2030; call for action [3, 12]. The major aim for bringing together these stakeholders was to inspire them to actively participate in a global effort toward strengthening rehabilitation in health systems, improving rehabilitation governance and investment; expanding a high-quality rehabilitation workforce; and enhancing rehabilitation data collection [3, 6]. WHO's call for action not only underscores the increasing need for rehabilitation, but also brings awareness to the role rehabilitation can play in achieving UN's Sustainable Development Goals (SDGs), specifically in ensuring that all people all over the world are able to experience good health and well-being $[3,13]$.
The Global Burden of Diseases (GBD), Injuries, and Risk Factors Study 2017 includes a comprehensive assessment of incidence, prevalence, and years lived with disability (YLDs) for 354 causes in 195 countries and territories from 1990 to 2017 [14, 15]. Previous GBD studies have shown how the decline of mortality rates from 1990 to 2016 has led to an increase in life expectancy, an ageing global population, and an expansion of the non-fatal burden of disease [14, 16]. Rehabilitation optimizes functioning and supports those with health conditions to remain as independent as possible, to participate in education, to be economically productive, and fulfill meaningful life roles $[3,4]$.

The burden of disability is unevenly distributed between low and high income countries with low and middle income countries carrying the greatest burden of disability compared to high income countries. Globally, it is estimated that there over 600 million PWDs of whom 400 million live in developing countries and about 80 million live in Africa $[5,8,17]$. United Nation's report maintains that about $40 \%$ of Africa's population consists of PWDs, including 10-15\% of school-age children [18] . This percentage would translate into about 300 million people with PWDs in Africa [18]. In Africa, data on utilization of rehabilitation services is still very limited. A population based study conducted among 33 countries in LMIC revealed generally limited access to rehabilitation services. In many countries, rehabilitation centers had collapsed or ceased function and others were not operating adequately [19]. In addition, an extensive survey of rehabilitation doctors in Sub-Saharan Africa identified only six, all in South Africa, for more than 780 million people, while Europe has more than 10, 000 and the United States has more than 7000 [20]. Furthermore, a survey of national societies of physical and rehabilitation medicine in Africa revealed that apart from the Northern African countries of Morocco, Tunisia, and Algeria which started the practice of rehabilitation in the twentieth century, almost all of the very few Sub-Sahara African countries with physical and rehabilitation medicine associations were formed in the early twenty-first century. In addition, to the countries with National Societies, there are some countries such as Benin, Ghana, Mali, Ethiopia, South Africa, and Uganda which do not have National Societies [21].

People with disabilities encounter several challenges in accessing rehabilitation services such as poor accessibility, high cost of accessing the services including transport costs, lack of awareness of the need for rehabilitation services, ignorance and long waiting times $[6,7]$. In addition, other factors include; lack of well-established national policy on physical rehabilitation, inadequate service provision, poor infrastructure development, lack of enough trained physical therapist 
professionals, misconception and traditional beliefs [6, $22,23]$. People with disabilities encounter numerous challenges in the societies including lack of accessible health facilities, poor education, unemployment, and high transport costs. People with disabilities are also known to have poor health, poor socioeconomic status, lower education levels which limit their participation in economic activities in the society than abled people [10, 24].

Many of the challenges encountered by PWDs in the societies including discrimination in service delivery, stigmatization from the wider community, discrimination in employment and business can be avoided $[5,8]$. Improved access to health care integrated with rehabilitation services generally improves health and well-being of PWDs including attaining better education, better employment, caring and participating in family, community and public life [6]. Increased access to rehabilitation services also lead to better overall socio-economic outcomes for people with disabilities and achievement of broader global development goals [10, 25].

The disease burden in Uganda is steadily increasing with communicable diseases including; Malaria, HIV/ AIDS, TB, respiratory tract infections, diarrhoea, and immunizable diseases accounting to over $50 \%$ of the total morbidity and mortality [14]. Uganda like other developing countries is also experiencing an epidemiological transition characterized by an increasing burden of non-communicable diseases (NCDs) including cancer, diabetes, cardiovascular diseases, violence and injuries especially road traffic injuries accompanied by population ageing $[14,15]$. The increasing double burden of diseases both communicable and non-communicable diseases in Uganda has resulted to the increase in the number of persons with disabilities [26, 27]. Rehabilitation is relevant for persons experiencing or likely to experience limitations in everyday functioning due to aging or health conditions, including chronic diseases or disorders, injuries or trauma [28].

According to Uganda Population Based Survey, the overall disability prevalence rate for population aged 2 years above stands at $12.4 \%$. Sex difference reveals that disability is higher among women (14.5\%) compared to men $(10.0 \%)$ and the disability prevalence rate was higher among those living in urban areas (15.0\%) compared to those in the rural areas (12.0\%) [29]. People with disabilities are one of the vulnerable groups of the population in Uganda and continue to face numerous challenges in terms of abuse and violations of their human rights $[30,31]$. Among the major types of rights violations are sexual abuse, discrimination in service delivery, stigmatization from the wider community, discrimination in employment and business and generally marginalization in terms of the economic, social and political rights [30, 31]. However, data on utilization of rehabilitation services to guide comprehensive health policy formulation at national and regional levels is still scarce.

Kawempe division is located in the Northern part of Kampala capital city (KCC) of Uganda. Due to the fact that the division is found in a low lying area of Kampala city with many informal settlements, residents in the slum areas of the Division must cope with natural location hazards like floods, garbage dumps, busy roads, power lines, open drains, water bodies, sinking soil industrial hazards, evictions, crime and community violence which increases their vulnerability to injuries and disabilities [32]. A report from Uganda Bureau of Statistics shows that Kawempe division accounts for $22.6 \%$ of all PWDs living in Kampala district [29]. Rehabilitation services are provided within Kawempe division at Mulago hospital physiotherapy department and Katalemwa rehabilitation center at a free and a subsidized cost to help improve the function, independence, and quality of life of people with physical disabilities. However, many people with physical disabilities do not utilize the services and the reasons are not known. There is also limited information about the prevalence of utilization of rehabilitation services among people with physical disabilities. Records from Mulago physiotherapy department and Katalemwa rehabilitation center shows that only $15.2 \%$ (3000 out of 19,776) PWDs in the division had utilized the services. However, results from facility records cannot be representative of PWDs utilizing rehabilitation services in the division because Mulago physiotherapy department and Katalemwa rehabilitation center serves a wide geographical area with Mulago hospital acting as national referral hospital of Uganda. In addition, such data is continuously being collected without analysis done over years to estimate the actual prevalence of utilization of rehabilitation services. Furthermore, the facility records captures all types of disabilities not only limited to physical disabilities which further makes it difficult to estimate the actual prevalence of utilization of rehabilitation services among people with physical disabilities. Therefore, the present study was conducted to determine the prevalence and factors associated with utilization of rehabilitation services among people with physical disabilities in Kawempe division, Kampala Uganda.

\section{Methods}

The study was conducted in Kawempe division. The division is located in the Northern part of Kampala the capital city of Uganda. The division is one of the five Divisions that make up Kampala City. Administratively, 
the division is made up of fifteen parishes [32]. Rehabilitation services are provided within Kawempe division at Mulago hospital physiotherapy department and Katalemwa rehabilitation center. Both facilities provide a wide range of services for mobility, vision, speech or communication and hearing impairments which include;- Therapeutic exercises modalities; Exercise table, Training stairs (steps), Weights (dumb bell, sand), Exercise bikes (stationary exercise bikes), Exercise (active and passive), Massage, Heat, Ice and Joint Mobilization. Assistive device technologies; Crutches, Wheel chairs, Walkers, Clappers, Prosthetics (artificial legs or arms), Orthotics (clappers, splint, brace, shoe insert or cast) for mobility impairment. Hearing aids, Cochlear implants for hearing impairment. Magnifiers, Ocular devices, Talking books (talking dictionaries), Large print and talking calculators, Closed circuit televisions (CCTV), Software such as screen reading and text enlargement programs for vision impairment Communication boards and Speech synthesizers for Speech or Communication impairments. Multidisciplinary rehabilitation service providers for both facilities include; - occupational therapists, orthotists and prosthetists, physiotherapists, psychologists, social workers, speech and language therapists.

The study population comprised of 318 people with physical disabilities aged 2 years and above living in Kawempe division. Physical disabilities included persons with permanent mobility, visual, speech and hearing impairment from any health condition whether congenital or acquired. The study design was a descriptive crosssectional study employing quantitative method of data collection. The sample size for this study was calculated using Kish Leslie (1964) formula for a single proportion. The study employed simple random sampling technique to select study respondents using computer generated random numbers. The people with physical disability were identified using Washington Group on disability statistics which has six questions related to six functional domains which include; mobility, hearing, visual, speech, self-care and cognition [33]. The tool was used in Uganda Demographic Health Surveys to identify PWDs $[29,34]$. The sampling frame with 1270 people with physical disabilities was obtained from Kawempe Division Disabled Community (KDDC) office located in Kamwokya along Mawanda Road which is working under the National Union of Disabled Persons of Uganda (NUDIPU). In order to reach out to the study participants, the leaders of PWDs disabled union helped to trace the study respondents in the division.

The dependent variable of the present study was prevalence of utilization of rehabilitation services which was defined as use of any rehabilitation service at any point in life. The overall prevalence of utilization of rehabilitation services was recorded as a binary variable where those who used rehabilitation services at any point in life responded "Yes" whereas those one who never used rehabilitation services responded "No". The same approach was used in a similar study conducted in Brazil [35]. The independent variables included; personal factors (age, sex, comorbidity conditions, education, income or socio economic status, motivation, attitudes and degree of disability) and environmental factors (accessible physical environment, accessible services, availability of caring family, attitude of health professionals, accessible transport, cost of services, waiting hours, availability of services, distance to the facility, accessible information, disabled people's organization and social attitude). Personal and environmental factors were reported by International Classification of Functioning, Disability and Health (ICF) model as either facilitators or barriers to utilizing rehabilitation services [1].

Quantitative data was collected using interviewer administered questionnaire by trained research assistants. The English questionnaire was translated into the local language (Luganda) and then back translated to English to ensure that the translated version does not alter the meaning of the questions prior to their use. In order to measure socio-economic status, principal components analysis (PCA) was run on the 11 household assets evaluated. These assets included owning: (1) a radio, (2) a television, (3) mobile phone, (4) a bicycle, (5) a motorcycle, (6) a motor vehicle, (7) a piece of land (8) a manufactured bed (9) Plastered wall, (10) cemented floor (11) electricity. The sensitivity and reliability test was conducted on the 11 house hold items. Cronbach's alpha coefficient was 0.8917 which was an implication that the variables were reliable to predict SES. The principal component on which most assets loaded was used to generate socio-economic status score for each participant. Participants were then grouped into SES quintiles (two descending groups). The same approach was used in Uganda Demographic Health Surveys [27, 34]. Education categories refer to the highest level of education attended, whether or not that level was completed. Education level of the study respondents was recorded as no education (not attended school or attained any level of education), primary, secondary and tertiary.

In order to measure distance; participants were asked the name of the nearby health facility with rehabilitation services. The exact distance of the respondents to the nearby facility with rehabilitation services was measured using Google earth. A distance of $5 \mathrm{~km}$ to the facility was recorded as an ideal distance and a distance above $5 \mathrm{~km}$ were recorded as a long distance to the facility. The same approach was used in Uganda demographic 
health surveys [27, 34]. Awareness of the study respondents about rehabilitation services was recorded as a binary variable by asking participants whether they have ever heard about physical rehabilitation services and facilities giving such services. Those who were aware of rehabilitation services answered "YES" and those who were not aware about rehabilitation services answered "NO".

Data was checked and cleaned for mistakes before entered into Micro soft excel. Thereafter, data was exported to STATA version 13 for analysis. Data was presented using appropriate frequency tables using percentages or proportions. At Bivariate analysis, cross tabulation between the dependent variable (utilization of rehabilitation services) and the independent variables (potential factors associated with utilization of rehabilitation services) was performed at a time to determine their level of significance using a chi square and a $P$ value $<0.05$ at $95 \%$ confidence interval. In order to select the candidate variables to include in the model, bivariate analysis was conducted using logistic regression analysis with a $p$-values $\leq 0.1$. Factors that were significantly associated with utilization of rehabilitation services at bivariate analysis and those that were not significant but with evidence from literature review indicating possible association with utilization of rehabilitation services was considered in the logistic regression model. Their respective Crude Odds Ratios (COR) were recorded at $95 \%$ confidence intervals. Then after; multivariate analysis was performed using the logistic regression model to determine factors that were significantly associated with utilization of rehabilitation services using backward elimination at $p<0.05$. Their respective Adjusted Odds Ratios (AOR) were recorded at 95\% confidence intervals. At this level, unknown and known confounding variables were controlled.

\section{Results}

Socio-demographic characteristics of people with physical disabilities in Kawempe division, Kampala, Uganda

A total of 318 study participants were included in the study. The mean age of the study participants was 27 years $(\mathrm{SD} \pm 12.9)$ and the mean distance of the study participants to the nearest health facility with rehabilitation services was $9.8 \mathrm{kms}(\mathrm{SD} \pm 2.9)$. Nearly three quarter $(69.5 \%)$ of the study participants were male. Less than half $(40.5 \%)$ of the study participants were in the age range of 19 to 34 years. More than a half $(52.52 \%)$ had attained primary education. Majority, (83.0\%) of the study respondents were from low socioeconomic quintile and more than half $(59.1 \%)$ of study participants had mobility impairments (Table 1).
Table 1 Socio-demographic characteristics of people with physical disabilities in Kawempe division

\begin{tabular}{|c|c|c|}
\hline Variable & $\begin{array}{l}\text { Frequency } \\
n=318\end{array}$ & $\begin{array}{l}\text { Percentage } \\
(\%)\end{array}$ \\
\hline \multicolumn{3}{|l|}{$\overline{\operatorname{Sex}}$} \\
\hline Male & 221 & 69.5 \\
\hline Female & 97 & 30.5 \\
\hline \multicolumn{3}{|c|}{ Age mean $=27(S D \pm 12.9)$} \\
\hline $2-18$ & 99 & 31.1 \\
\hline $19-34$ & 129 & 40.6 \\
\hline 35 above & 90 & 28.3 \\
\hline \multicolumn{3}{|l|}{ Religion } \\
\hline Catholic & 47 & 14.8 \\
\hline Protestant & 74 & 23.3 \\
\hline Christian Pentecostal & 116 & 36.5 \\
\hline Muslim & 81 & 25.5 \\
\hline \multicolumn{3}{|l|}{ Marital status } \\
\hline Single & 194 & 61.0 \\
\hline Married & 46 & 14.5 \\
\hline Divorced/ separated & 78 & 24.5 \\
\hline \multicolumn{3}{|l|}{ Education level } \\
\hline None & 44 & 13.8 \\
\hline Primary & 167 & 52.5 \\
\hline Secondary & 107 & 33.7 \\
\hline \multicolumn{3}{|l|}{ Socioeconomic quintiles } \\
\hline Low & 264 & 83.0 \\
\hline High & 54 & 17.0 \\
\hline \multicolumn{3}{|l|}{ Occupation } \\
\hline Not employed & 144 & 45.3 \\
\hline Employed & 174 & 54.7 \\
\hline \multicolumn{3}{|l|}{ Type of Disability } \\
\hline Vision speech & 72 & 22.6 \\
\hline Hearing & 58 & 18.2 \\
\hline Mobility & 188 & 59.1 \\
\hline \multicolumn{3}{|l|}{ Awareness } \\
\hline No & 200 & 62.8 \\
\hline Yes & 118 & 37.1 \\
\hline \multicolumn{3}{|l|}{ Nature of disability } \\
\hline Congenital & 56 & 17.6 \\
\hline Acquired & 262 & 82.4 \\
\hline \multicolumn{3}{|l|}{ Cause of disability } \\
\hline Road traffic crashes & 101 & 31.8 \\
\hline Infection & 158 & 49.7 \\
\hline Other causes & 59 & 18.6 \\
\hline \multicolumn{3}{|c|}{ Distance mean 9.8 km (SD \pm 2.9$)$} \\
\hline $0-5 \mathrm{~km}$ & 26 & 8.2 \\
\hline $6 \mathrm{~km}$ above & 292 & 92.0 \\
\hline \multicolumn{3}{|l|}{ Family support } \\
\hline No & 111 & 34.9 \\
\hline Yes & 207 & 65.1 \\
\hline
\end{tabular}

Prevalence of the utilization of rehabilitation services among people with physical disabilities in Kawempe division, Uganda

The study revealed prevalence $26.4 \%$ of utilization of rehabilitation services. The prevalence of utilization of 
rehabilitation services was significantly different among study participants with different education levels; $p=0.001$. In addition, the prevalence of utilization of rehabilitation services was significantly different among respondents with different socioeconomic quintiles and level of awareness about rehabilitation services respectively; (Table 2).

\section{Factors associated with utilization of rehabilitation services among people with physical disabilities in Kawempe division}

At bivariate logistic regression analysis, factors that were significantly associated with utilization of rehabilitation services among people with physical disabilities included age, being in the age range of 19-34 years (COR: 2.13; 95\% CI: $1.17-3.88)$ compared to being in the age range of 2-18 years, education level, having attained secondary school education (COR: 5.77 95\% CI: 2.25-14.78) compared to no education, occupation, being employed (COR: 2.27; 95\% CI: 1.34-3.85) compared to no employment, socio economic status, having a high social economic status (COR: 4.0; 95\% CI: 2.17-7.36) compared to low socio economic status, type of disability, having a mobility impairment (COR: 6.98; 95\% CI: (2.88-16.9) compared to vision or speech impairment, awareness, being aware of rehabilitation services (COR: 7.0; 95\% CI: 4.03-12.17) compared to being un aware of the services, nature of disability, having acquired disability (COR: 2.91; 95\% CI:1.26-6.72) compared to congenital disability. Cause of disability, having acquired a disability by an infection had $87 \%$ less odds of utilizing rehabilitation services (COR: 0.13; 95\% CI: 0.71-0.24) compared to a road traffic crash. Other factors like sex, religion, marital status, and distance to the facility with rehabilitation services were not significantly associated with utilization of rehabilitation services (Table 3).

After performing multivariate analysis, variables that were significantly associated with utilization of rehabilitation services included; age (AOR: 0.30; 95\% CI: 0.120.74 ), socioeconomic status (AOR: 2.13 ; 95\% CI: $1.03-$ 4.41), education level (AOR: 4.3; 95\% CI: 1.34-13.91) and awareness of the participants about the services (AOR: 5.1; 95\% CI: 2.74-9.54) p value $\leq 0.05$, (Table 4).

After adjusting for socioeconomic status, education level and awareness of the participants about the services, people with physical disabilities aged 34 years and above had $70 \%$ less odds of utilizing rehabilitation services than those aged 2-18 years (AOR: 0.30; 95\% CI: $0.12-0.74 ; p=0.009$ ). After adjusting for age, socioeconomic status, and awareness of the participants about the services, the odds of utilizing rehabilitation services was 4.3 times higher among people with disabilities who had attained secondary education compared to those no education (AOR: 4.3; 95\% CI: 1.34-13.91; $p=0.014$ ).
After adjusting for age, education level, and awareness of the participants about the services, the odds of utilizing rehabilitation services was 2.1 times higher among people with disabilities from higher socio economic quintile compared to those from low socio economic quintile (AOR: 2.13; 95\% CI: $1.03-4.41 ; p=0.042$ ). After adjusting for age, education level, and socioeconomic status, people with physical disabilities who were aware of rehabilitation services had 5.1 times more odds of utilizing rehabilitation services than those who were not aware of the services (AOR: 5.1; 95\% CI: 2.74-9.54; $p=0.001)$.

\section{Discussion}

This study revealed a prevalence of $26.42 \%$ of the utilization rehabilitation services among people with physical disability in the study area. According to WHO's report, rehabilitation is an essential component of quality health services that should be included in Universal Health Coverage. This means that all individuals should be able to access quality rehabilitation services without fear of financial hardships [3]. Therefore, the prevalence of utilization of rehabilitation services was considered very low in the study area. The prevalence of utilization of rehabilitation services obtained in this study is almost consistent with other studies conducted in Southern Brazil [36], South Africa [37], and Beijing China [38] with the prevalence of 20, 22.5 and $27 \%$ respectively. The result of this study was much lower than the previous studies conducted among people with physical disabilities in Lages state of Santa Catarina [35] and Geneva Switzerland [39] with the prevalence of 33.2 and $37.2 \%$ respectively, but higher than previous studies conducted in Brazil [40], USA [41] and Taiwan [42] with the prevalence of $14.5,6.8$ and $11.02 \%$ respectively. Socioeconomic and geographical variations might be the reason for the different prevalence's of the utilization of rehabilitation services among people with physical disabilities across countries and regions.

In the present study, majority (69.5\%) of the study respondents were male. The finding is consistent with a previous study conducted in South Africa [37] but inconsistent with a population based survey conducted in Uganda which showed that disability was higher among women compared to men [29]. This could be because the present study was conducted in an urban area where men got involved in many occupational activities like motorcyclists, taxi drivers and street vending which increases their risk of getting involved in accidents thus sustaining injuries and disabilities. In addition, Uganda has been reported to have high rate of accidents among commercial motorcyclists with Mulago hospital alone receiving five (5) to twenty (20) accident victims of commercial motorcyclists on a daily basis [43]. 
Table 2 Prevalence of the utilization of rehabilitation services among people with physical disabilities in Kawempe division

Variables Utilization of physical rehabilitation $P$ value

\begin{tabular}{lll} 
& \multicolumn{2}{l}{ services } \\
\cline { 2 - 3 } & Yes (\%) & No (\%) \\
\hline$N=318$ & $84(26.4)$ & $234(73.6)$
\end{tabular}

Sex

$\begin{array}{llll}\text { Female } & 30(35.7) & 67(28.6) & 0.227 \\ \text { Male } & 54(64.3) & 167(71.4) & \\ \text { Age } & & & \\ 35 \text { above } & 16(19.1) & 74(31.6) & 0.003\end{array}$

$\begin{array}{lll}35 \text { above } & 16(19.1) & 74(31.6) \\ 19-34 & 47(55.9) & 82(35.0) \\ 2-18 & 21(25.0) & 78(33.3)\end{array}$

Religion

$\begin{array}{lll}\text { Muslim } & 21(25.0) & 60(25.6) \\ \text { Pentecostal } & 31(36.9) & 85(36.3) \\ \text { Protestant } & 15(17.8) & 59(25.2) \\ \text { Catholic } & 17(20.2) & 30(12.8)\end{array}$

Education level

$\begin{array}{lll}\text { Secondary } & 51(60.7) & 56(23.9) \\ \text { Primary } & 27(32.1) & 140(59.8) \\ \text { None } & 6(7.1) & 38(16.2)\end{array}$

Marital status

$\begin{array}{llll}\text { Divorced/Separated } & 18(21.4) & 60(25.6) & 0.656 \\ \text { Married } & 14(16.7) & 32(13.7) & \end{array}$

Single/Never married $52(51.9) \quad 142(60.7)$

Occupation

$\begin{array}{lll}\text { Employed } & 58(69.1) & 116(49.6) \\ \text { Not employed } & 26(30.9) & 118(50.4) \\ \text { SES Quintiles } & & \\ \text { High } & 28(33.3) & 26(11.1) \\ \text { Low } & 56(66.7) & 208(88.9)\end{array}$

Distance

$\begin{array}{llll}6 \text { km above } & 74(88.1) & 218(93.16) & 0.146 \\ 0-5 \mathrm{~km} & 10(11.9) & 16(6.4) & \\ \begin{array}{l}\text { Disability } \\ \text { Mobility }\end{array} & 73(86.9) & 115(49.1) & 0.001 \\ \text { Hearing } & 5(5.9) & 53(22.7) & \\ \text { Vision speech } & 6(7.1) & 66(28.2) & \\ \text { Awareness } & & & \\ \text { Yes } & 59(70.2) & 59(25.5) & 0.001 \\ \text { No } & 25(29.8) & 175(75.8) & \\ \text { Nature } & & & \\ \text { Acquired } & 77(91.7) & 185(79.1) & 0.009 \\ \text { Congenital } & 7(8.3) & 49(20.9) & 0.001 \\ \text { Cause of disability } & & & \\ \text { Others } & 11(13.1) & 48(20.5) & \end{array}$

Table 2 Prevalence of the utilization of rehabilitation services among people with physical disabilities in Kawempe division (Continued)

\begin{tabular}{|c|c|c|c|}
\hline \multirow[t]{2}{*}{ Variables } & \multicolumn{2}{|c|}{$\begin{array}{l}\text { Utilization of physical rehabilitation } \\
\text { services }\end{array}$} & \multirow[t]{2}{*}{$P$ value } \\
\hline & Yes (\%) & No (\%) & \\
\hline Infection & $20(23.8)$ & $138(59.0)$ & \\
\hline Road traffic crash & $53(63.1)$ & $48(20.5)$ & \\
\hline \multicolumn{4}{|l|}{ Family support } \\
\hline Yes & $62(73.8)$ & $145(62.0)$ & 0.051 \\
\hline No & $22(26.2)$ & 89 (38.0) & \\
\hline
\end{tabular}

In this study, age, socioeconomic status, education level and awareness of the participants about the services were significantly associated with utilization of physical rehabilitation services.

In this study, age was significantly associated with utilization of rehabilitation services and people with physical disability aged 34 years and above had $70 \%$ less odds of utilizing physical rehabilitation services than those aged $2-18$ years. This could be because elders are unlikely to utilize the physical rehabilitation services due to poor socioeconomic status, low education level, high rate of unemployment and long distance to the facility which is evident in this study. The study findings are consistent with previous studies conducted in United States of America [41], South Africa [37] which reported low level of utilization of rehabilitation services among elderly population but inconsistent with other studies conducted in Brazil [35, 36] and China [42] which revealed that the use of rehabilitation services was higher among elders aged 35-60 years. The difference in study findings could be partly attributed to the variation in the social demographic profile of different countries. Therefore, the government and other relevant stakeholders should deliver community based rehabilitation services to increase access to these services in the communities.

In this study, higher socioeconomic status was significantly associated with increased utilization of rehabilitation services. This could be because participants from higher socioeconomic quintile might have better education and financial ability to utilize rehabilitation services unlike their counterparts from low socioeconomic quintile. Similar results were reported from other studies conducted in India [44] and Brazil $[35,36]$. Therefore, the government should establish community based rehabilitation (CBR) programs within the community and provide rehabilitation services in primary health care facilities to reduce the transport costs and increase accessibility to the services.

In the present study, higher education level was significantly associated with increased utilization of rehabilitation 
Table 3 Bivariate analysis of the factors associated with utilization of rehabilitation services among people with physical disabilities in Kawempe division

\begin{tabular}{|c|c|c|c|}
\hline \multirow[t]{2}{*}{ Variables } & $\begin{array}{l}\text { Utilization of } \\
\text { physical } \\
\text { rehabilitation } \\
\text { services }\end{array}$ & \multirow[t]{2}{*}{$\begin{array}{l}\text { Unadjusted } \\
\text { OR }(95 \% \mathrm{Cl})\end{array}$} & \multirow[t]{2}{*}{$P$ value } \\
\hline & Yes (\%) No (\%) & & \\
\hline
\end{tabular}

Sex

$\begin{array}{lllll}\text { Female } & 30(35.7) & 67(28.6) & 1.38(0.82-2.35) & 0.228 \\ \text { Male } & 54(64.3) & 167(71.4) & 1.0 & \\ \text { Age } & & & & \\ 35 \text { above } & 16(19.1) & 74(31.6) & 0.8(0.39-1.66) & 0.553 \\ 19-34 & 47(55.9) & 82(35.0) & 2.13(1.17-3.88)^{*} & 0.014 \\ 2-18 & 21(25.0) & 78(33.3) & 1.0 & \end{array}$

Religion

$\begin{array}{lllll}\text { Muslim } & 21(25.0) & 60(25.6) & 0.62(0.28-1.34) & 0.223 \\ \text { Pentecostal } & 31(36.9) & 85(36.3) & 0.64(0.31-1.32) & 0.232 \\ \text { Protestant } & 15(17.8) & 59(25.2) & 0.45(0.19-1.02) & 0.056 \\ \text { Catholic } & 17(20.2) & 30(12.8) & 1.0 & \end{array}$

Education level

\begin{tabular}{|c|c|c|c|c|}
\hline Secondary & $51(60.7)$ & $56(23.9)$ & $5.77(2.25-14.78)^{* *}$ & 0.001 \\
\hline Primary & $27(32.1)$ & $140(59.8)$ & $1.22(0.47-3.17)$ & 0.681 \\
\hline None & $6(7.1)$ & $38(16.2)$ & 1.0 & \\
\hline \multicolumn{5}{|l|}{ Marital status } \\
\hline $\begin{array}{l}\text { Divorced/ } \\
\text { Separated }\end{array}$ & $18(21.4)$ & $60(25.6)$ & $0.82(0.44-1.52)$ & 0.525 \\
\hline Married & $14(16.7)$ & $32(13.7)$ & $1.19(0.59-2.42)$ & 0.620 \\
\hline $\begin{array}{l}\text { Single/Never } \\
\text { married }\end{array}$ & $52(61.9)$ & $142(60.7)$ & 1.0 & \\
\hline \multicolumn{5}{|l|}{ Occupation } \\
\hline Employed & $58(69.1)$ & $116(49.6)$ & $2.27(1.34-3.85)^{*}$ & 0.002 \\
\hline Not employed & $26(30.9)$ & $118(50.4)$ & 1.0 & \\
\hline \multicolumn{5}{|l|}{ SES Quintiles } \\
\hline High & $28(33.3)$ & $26(11.1)$ & $4.0(2.17-7.36)^{* *}$ & 0.001 \\
\hline Low & $56(66.7)$ & $208(88.9)$ & 1.0 & \\
\hline \multicolumn{5}{|l|}{ Distance } \\
\hline $6 \mathrm{~km}$ above & $74(88.1)$ & $218(93.16)$ & $0.54(0.24-1.25)$ & 0.151 \\
\hline $0-5 \mathrm{~km}$ & $10(11.9)$ & $16(6.4)$ & 1.0 & \\
\hline \multicolumn{5}{|l|}{ Disability } \\
\hline Mobility & $73(86.9)$ & $115(49.1)$ & $6.98(2.88-16.9)^{* *}$ & 0.001 \\
\hline Hearing & $5(5.9)$ & $53(22.7)$ & $1.0(0.30-3.59)$ & 0.953 \\
\hline Vision speech & $6(7.1)$ & $66(28.2)$ & 1.0 & \\
\hline \multicolumn{5}{|l|}{ Awareness } \\
\hline Yes & $59(70.2)$ & $59(25.5)$ & $7.0(4.03-12.17)^{* *}$ & 0.001 \\
\hline No & $25(29.8)$ & $175(75.8)$ & 1.0 & \\
\hline
\end{tabular}

Table 3 Bivariate analysis of the factors associated with utilization of rehabilitation services among people with physical disabilities in Kawempe division (Continued)

\begin{tabular}{|c|c|c|c|c|}
\hline \multirow[t]{2}{*}{ Variables } & \multicolumn{2}{|c|}{$\begin{array}{l}\text { Utilization of } \\
\text { physical } \\
\text { rehabilitation } \\
\text { services }\end{array}$} & \multirow[t]{2}{*}{$\begin{array}{l}\text { Unadjusted } \\
\text { OR }(95 \% \mathrm{Cl})\end{array}$} & \multirow[t]{2}{*}{$P$ value } \\
\hline & Yes (\%) & No (\%) & & \\
\hline \multicolumn{5}{|l|}{ Nature } \\
\hline Acquired & 77 (91.7) & $185(79.1)$ & $2.91(1.26-6.72)^{*}$ & 0.012 \\
\hline Congenital & $7(8.3)$ & $49(20.9)$ & 1.0 & \\
\hline \multicolumn{5}{|l|}{ Cause of disability } \\
\hline Others & $11(13.1)$ & $48(20.5)$ & $0.2(0.10-0.45)^{* *}$ & 0.001 \\
\hline Infection & $20(23.8)$ & $138(59.0)$ & $0.13(0.71-0.24)^{* *}$ & 0.001 \\
\hline Road traffic crash & $53(63.1)$ & $48(20.5)$ & 1.0 & \\
\hline \multicolumn{5}{|l|}{ Family support } \\
\hline Yes & $62(73.8)$ & $145(62.0)$ & $1.72(0.99-3.0)$ & \\
\hline No & $22(26.2)$ & $89(38.0)$ & 1.0 & \\
\hline
\end{tabular}

services. This could be because participants who had attained higher level of formal education are more likely to have better knowledge about the benefits of utilizing rehabilitation services. This result is consistent with other studies conducted in India [45], China [46] and Brazil [35].Therefore, the government should provide more education opportunities to people with physical disabilities like vocational training and state scholarships targeting people with physical disabilities.

Furthermore, this study revealed that awareness of the participants about rehabilitation services was significantly associated with utilization of rehabilitation services and people with physical disabilities who were aware of physical rehabilitation services had 5.1 times more odds of utilizing physical rehabilitation services than those who were not aware of the service (AOR: 5.1; 95\% CI: 2.74-9.54; $p=0.001$ ). This could be because participants who were aware of rehabilitation services were more likely to know the benefits, available services and facilities providing such services which could make them to utilize the services unlike their counterparts who were not aware of the services. Similar findings were reported by previous studies conducted in South Africa [37], India [44] and China [47]. Therefore, the government and other non-government organizations should increase sensitization and awareness of rehabilitation services, their benefits, available services and facilities providing such services among people with physical disabilities and the general public.

A number of challenges were also pointed out in the findings of this study. First, it appears that rehabilitation 
Table 4 Multivariate analysis of the factors associated with utilization of rehabilitation services among people with physical disabilities in Kawempe division.

\begin{tabular}{|c|c|c|c|c|c|c|}
\hline \multirow[t]{2}{*}{ Variables } & \multicolumn{2}{|c|}{ Utilization of physical rehabilitation services } & \multirow[t]{2}{*}{ Unadjusted OR(95\%Cl) } & \multirow[t]{2}{*}{$\mathrm{P}$ value } & \multirow[t]{2}{*}{ Adjusted OR(95\%Cl) } & \multirow[t]{2}{*}{ P value } \\
\hline & Yes (\%) & No (\%) & & & & \\
\hline \multicolumn{7}{|l|}{$\overline{\operatorname{Sex}}$} \\
\hline Female & $30(35.7)$ & $67(28.6)$ & $1.38(0.82-2.35)$ & 0.228 & & \\
\hline Male & $54(64.3)$ & 167(71.4) & 1.0 & & & \\
\hline \multicolumn{7}{|l|}{ Age } \\
\hline 35 above & 16(19.1) & 74(31.6) & $0.8(0.39-1.66)$ & 0.553 & $0.30\left(0.120 .74^{*}\right.$ & 0.009 \\
\hline $19-34$ & $47(55.9)$ & $82(35.0)$ & $2.13(1.17-3.88)^{*}$ & 0.014 & $0.50(0.21-1.17)$ & 0.108 \\
\hline $2-18$ & $21(25.0)$ & 78(33.3) & 1.0 & & 1.0 & \\
\hline \multicolumn{7}{|l|}{ Education level } \\
\hline Secondary & $51(60.7)$ & $56(23.9)$ & $5.77(2.2514 .78)^{* *}$ & 0.001 & $4.3(1.34-13.91)^{*}$ & 0.014 \\
\hline Primary & 27(32.1) & 140(59.8) & $1.22(0.47-3.17)$ & 0.681 & $0.87(0.31-2.48)$ & 0.801 \\
\hline None & $6(7.1)$ & $38(16.2)$ & 1.0 & & 1.0 & \\
\hline \multicolumn{7}{|l|}{ Occupation } \\
\hline Employed & $58(69.1)$ & 116(49.6) & $2.27(1.34-3.85)^{*}$ & 0.002 & & \\
\hline Not employed & $56(66.7)$ & $118(50.4)$ & 1.0 & & & \\
\hline \multicolumn{7}{|l|}{ SES Quintiles } \\
\hline High & 28(33.3) & $26(11.1)$ & $4.0(2.17-7.36)^{* *}$ & 0.001 & $2.13(1.03-4.41)^{*}$ & 0.042 \\
\hline Low & $56(66.7)$ & 208(88.9) & 1.0 & & 1.0 & \\
\hline \multicolumn{7}{|l|}{ Disability } \\
\hline Mobility & 73(86.9) & $115(49.1)$ & $6.98(2.88-16.9)^{* *}$ & 0.001 & & \\
\hline Hearing & $5(5.9)$ & $53(22.7)$ & $1.0(0.30-3.59)$ & 0.953 & & \\
\hline Vision speech & $6(7.1)$ & $66(28.2)$ & 1.0 & & & \\
\hline \multicolumn{7}{|l|}{ Awareness } \\
\hline Yes & $59(70.2)$ & $59(25.5)$ & $7.0(4.0312 .17)^{* *}$ & 0.001 & $5.1(2.74-9.54)^{* *}$ & 0.001 \\
\hline No & 25(29.8) & 175(75.8) & 1.0 & & 1.0 & \\
\hline \multicolumn{7}{|l|}{ Nature } \\
\hline Acquired & 77(91.7) & 185(79.1) & $2.91(1.26-6.72)^{*}$ & 0.012 & & \\
\hline Congenital & $7(8.3)$ & 49(20.9) & 1.0 & & & \\
\hline \multicolumn{7}{|l|}{ Cause of disability } \\
\hline Others & 11(13.1) & $48(20.5)$ & $0.2(0.10-0.45)^{* *}$ & 0.001 & & \\
\hline Infection & $20(23.8)$ & 138(59.0) & $0.13(0.710 .24)^{* *}$ & 0.001 & & \\
\hline Road traffic crash & $53(63.1)$ & $48(20.5)$ & 1.0 & & & \\
\hline
\end{tabular}

services such as therapeutic exercise modalities, assistive device technologies, hearing aids, speech therapies and vision aids are essentially unknown to people with physical disabilities and health professionals from other disciplines. The study findings are consistent with other studies conducted in Switzerland [48] and Urban Uganda [23]. Given the increasing number of people with disabilities in Uganda, it appears that the task of sensitizing healthcare professionals, policy makers and the public about the available rehabilitative services is of paramount importance. The results of this study might also assist in the modification of programs that have previously been developed and aimed at training individuals to deliver community rehabilitation services.

\section{Conclusion}

The study revealed a prevalence of $26.4 \%$ of the utilization rehabilitation services among people with physical disabilities in Kawempe division, Uganda. Factors that were significantly associated with utilization of rehabilitation services included age, socioeconomic status, education level and awareness of the participants about the services. Therefore, the government and other 
relevant stake holders should increase sensitization and awareness of rehabilitation services to people with physical disabilities, healthcare professionals and the general public, provide more education opportunities to people with physical disabilities, establish a public funding mechanism targeting people with physical disabilities, integrate basic rehabilitation services within the existing health care service delivery and establish community based rehabilitation centers to increase access to rehabilitation services.

\section{Abbreviations}

AOR: Adjusted Odds Ratio; CBR: Community Based Rehabilitation; COR: Crude Odds Ratio; CRPD: Convention of the Rights of Persons with Disabilities; DALYs: Disability Adjusted Life Years; KCCA: Kampala Capital City Authority; LMICs: Low and Middle-Income Countries; $\mathrm{MOH}$ : Ministry of Health; NUDIPU: National Union of Disabled Persons of Uganda; PWDs: People with Disabilities; PWPDs: People with Physical Disabilities; UN: United Nation; UNAPD: Uganda National Action on Physical Disability; WHO: World Health Organization

\section{Acknowledgements}

My unlimited and heartfelt thanks go to the staff Makerere University -John Hopkins University CHRONIC TRIAD program most especially Dr. Olive Kobusingye, Dr. Abdul gafoor Bachani, Dr. Adinan Hyder, Dr. Nino Paichadze, Dr. Jacob A. Bentley and Ms. Grace Magambo for the financial support and technical guidance they offered me.

I also extend my sincere gratitude to staff Kawempe Division Disabled Community and Mr. Rwakabaale Godfrey the Town Clerk Kawempe Division for the support and permission to conduct the study in the Division.

\section{Source of funding}

Funding for this study came from Makerere University-Johns Hopkins University Chronic Consequences of Trauma, Injuries, and Disability across the Lifespan in Uganda Program, grant \#D43TW009284 from the Fogarty International Center, U.S. National Institute of Health (NIH). However, funders didn't participate in the whole study process including design of the study and data collection, interpretation of the data and writing a manuscript.

\section{Authors' contributions}

ZS: conceptualized and designed the study and obtained ethical clearance. He led in the writing of the drafts of the manuscript and revised the paper for substantial intellectual content.

OK: participated in the writing of the methodology and the draft of the manuscript.

NP: participated in scientific editing and critical revision of the manuscript to ensure appropriateness and intellectual content.

RN: participated in data collection and analysis of the data.

FO: participated in the cleaning and analysis of the data.

AMB: contributed in the design of the study and participated in the scientific editing of the draft.

LMA: participated in the writing of the methodology and results.

$\mathrm{BH}, \mathrm{DK}$ and JAB: were the overall supervisor of the study and advised on the type of analysis and methodology.

All authors read and approved the final manuscript.

\section{Availability of data and materials}

The datasets used or analyzed during the current study are available from the corresponding author on reasonable request.

\section{Ethics approval and consent to participate}

Approval to conduct the study was sought from the Institutional Review Board (IRB) of Makerere University School of Public Health and National Council of Science and Technology. Permission to conduct the study was sought from Kawempe division authorities. The study participants were requested to give a free written informed consent in order to participate in the study prior to data collection. For participants below 18 years, informed consent was sought from their parents or care takers and children also assented to the study. Confidentiality of participant information was ensured by use of unique identifiers for study participants. However, results may be availed to the relevant parties and may also be published in the relevant journals.

\section{Consent for publication}

Not applicable.

\section{Competing interests}

The funders had no role in the whole study process, decision to publish or manuscript preparation.

\section{Author details}

${ }^{1}$ Department of Disease Control and Environmental Health, Makerere University School of Public Health, College of Health Sciences, New Mulago Hill Hospital Complex, P.O Box 7072, Kampala, Uganda. ${ }^{2}$ Department of Maternal and Child health, Makerere University College of Health Sciences, Kampala, Uganda. ${ }^{3}$ Department of Health Policy, Planning and Management, Makerere University School of Public Health, Kampala, Uganda. ${ }^{4}$ Department of International Health and International Injury Research Unit, Johns Hopkins Bloomberg School of Public Health, Baltimore, MD, USA. ${ }^{5}$ Department of Global Health, Milken Institute School of Public Health, the George Washington University, Washington, DC, USA.

Received: 1 April 2019 Accepted: 12 December 2019

Published online: 27 December 2019

\section{References}

1. WHO: International Classification of Functioning, Disability and Health: ICF: World Health Organization; 2001.

2. Stucki G, Cieza A, Melvin J. The international classification of functioning, disability and health: a unifying model for the conceptual description of the rehabilitation strategy. J Rehabil Med. 2007;39(4):279-85.

3. Rehabilitation 2030: a call for action [https://www.who.int/disabilities/care/ Rehab2030MeetingReport_plain_text_version.pdf].

4. Gimigliano F, Negrini S. The World Health Organization "rehabilitation 2030 a call for action". Eur J Phys Rehabil Med. 2017;53(2):155-68.

5. WORLD REPORT ON DISABILITY [http://www.who.int/about/].

6. Krug E, Cieza A. Strengthening health systems to provide rehabilitation services. Neuropsychol Rehab. 2019;29(5):672-4.

7. Negrini S. The possibilities and challenges of" rehabilitation 2030: a call for action" by the World Health Organization: a unique opportunity not to be missed. Eur J Phys Rehab Med. 2017:53(2):169.

8. Global Disability Action Plan 2014-2021 [http://www.who.int/about/]

9. Kostanjsek N, Good A, Madden RH, Üstün TB, Chatterji S, Mathers CD, Officer A. Counting disability: global and national estimation. Disabil Rehabil. 2013; 35(13):1065-9.

10. 66th World Health Assembly adopts resolution calling for better health care for people with disabilities [www.who.int/disabilities/media/news/2013/28_ 05/en/]

11. Stein, MA, Lord, JE. The domestic incorporation of human rights law and the United Nations convention on the rights of persons with disabilities. 2008.

12. Corner CR. Cochrane Rehabilitation: report of the first year of work. Work. 2018:54:463-5.

13. SDGs U: United nations sustainable development goals. UN Org 2015

14. GBD: Global Burden of Disease Study 2017 (GBD 2017) Data Resources. In.; 2017

15. James SL, Abate D, Abate KH, Abay SM, Abbafati C, Abbasi N, Abbastabar H, Abd-Allah F, Abdela J, Abdelalim A. Global, regional, and national incidence, prevalence, and years lived with disability for 354 diseases and injuries for 195 countries and territories, 1990-2017: a systematic analysis for the global burden of disease study 2017. Lancet. 2018;392(10159):1789-858.

16. Vos $T$, Abajobir AA, Abate KH, Abbafati $C$, Abbas KM, Abd-Allah $F$ Abdulkader RS, Abdulle AM, Abebo TA, Abera SF. Global, regional, and national incidence, prevalence, and years lived with disability for 328 diseases and injuries for 195 countries, 1990-2016: a systematic analysis for the global burden of disease study 2016. Lancet. 2017;390(10100):1211-59.

17. Disability in Africa, [http://www.ascleiden.nl/content/webdossiers/disabilityafrica]

18. Disability in Africa [https://www.ascleiden.nl/content/webdossiers/disabilityafrica] 
19. Equal basis [www.the-monitor.org/media/1717975/EqualplusBasisplus2014 plusFinal.pdf]

20. Haig AJ, Im J, Adewole D, Nelson V, Krabak B. The practice of physical and rehabilitation medicine in sub-Saharan Africa and Antarctica: a white paper or a black mark? J Rehabil Med. 2009;41(6):401-5.

21. Tannor A. 7.6 The organizations of physical and rehabilitation medicine in the world: Physical and rehabilitation medicine in Africa. J Int Soc Phys Rehab Med. 2019;2(2):156.

22. Gutenbrunner C, Nugraha B. Physical and rehabilitation medicine: responding to health needs from individual care to service provision. Eur Phys Rehab Med. 2017;53(1):1-6.

23. Harms OK. Factors that influence the use of rehabilitation services in an urban Ugandan hospital. Int J Rehabil Res. 2003;26(1)

24. Bowling A. Research methods in health: investigating health and health services: McGraw-hill education (UK); 2014.

25. Skempes D, Bickenbach J. Strengthening rehabilitation for people with disabilities: a human rights approach as the essential next step to accelerating global progress. Am J Phys Med Rehab. 2015;94(10):823-8.

26. Guwatudde D, Mutungi G, Wesonga R, Kajjura R, Kasule H, Muwonge J, Ssenono V, Bahendeka SK. The epidemiology of hypertension in Uganda: findings from the national non-communicable diseases risk factor survey. PLoS One. 2015;10(9):e0138991.

27. UBOS. Uganda demographic and health survey 2016: key indicators report. Kampala, Uganda: UBOS, and Rockville, Maryland, USA: UBOS and ICF. In.; 2016.

28. Cieza A. Rehabilitation the health strategy of the 21st century, really? Archives of physical medicine and rehabilitation 2019.

29. The National Population and Housing Census 2014-Main Report, Kampala Uganda [www.ubos.org]

30. NUDIPU: Disability and Human Rights. In.; 2013

31. Allen K: Oppression through omission: the human rights case of persons with albinism in Uganda. Unpublished master thesis 2010: 353-382.

32. KCCA: Kampala profiles; Kawempe. 2014.

33. History of the Washington Group on Disability Statistics [http://www. washingtongroup-disability.com/about/history/]

34. UBOS: Uganda Demographic and Health Survey 2011. Kampala, Uganda: UBOS and Calverton, Maryland: ICF International Inc. In.; 2011

35. Moretto LCLG, Boing AF, Arruda MP. Prevalence of the use of physical therapy services among the urban adult population of Lages. Santa Catarina. 2009;13(2):130-5.

36. Siqueira FV, Facchini LA, Hallal PC. Epidemiology of physiotherapy utilization among adults and elderly. Rev Saude Publica. 2005;39(4):662-8.

37. Kotsokoane F, Skaal L, Tshabalala M. Factors influencing the utilisation of community-based rehabilitation services by people with disability in Tshwane, Gauteng Province, South Africa: utilization of primary health care services. Afr J Phys Heal Educ, Recreation and dance: conducting responsive research to address public health challenges. Supplement 22 2015, 21: 287-295.

38. Maulik PK, Mascarenhas MN, Mathers CD, Dua T, Saxena S. Prevalence of intellectual disability: a meta-analysis of population-based studies. Res Dev Disabil. 2011;32(2):419-36.

39. Anne lubbeke Rs, Bernard Grab, Fracois Herman. Upper extremity fracture in elderly, consquence on utilization of rehabilitation care 2005(17):276-280.

40. Amorim JSC, da Silva SLA, Pereira LSM, Dias RC. Access to physical therapy services and their use by elderly persons with low back pain. ConScientiae Saúde. 2013;12(4):528.

41. Carter SK, Rizzo JA. Use of outpatient physical therapy services by people with musculoskeletal conditions. Phys Ther. 2007;87(5):497-512.

42. Chang Y-C, Lin J-D, Tung H-J, Chiang P-H, Hsu S-W. Outpatient physical therapy utilization for children and adolescents with intellectual disabilities in Taiwan: a population-based nationwide study. Res Dev Disabil. 2014;35(2): 498-505.

43. Kigera J, Naddumba E. Patterns of injuries after road traffic crashes involving Bodabodas. Ann Afr Surg. 2010;5(1)

44. Padmamohan J, Nair M, Devi SR, Nair S, Leena M, Kumar GS. Utilization of rehabilitation services by rural households with disabled pre-school children. Indian Pediatr. 2009;46:579-82.

45. Srivastava DK, Khan JA, Pandey S, Pillai DS, Bhavsar AB. Awareness and utilization of rehabilitation services among physically disabled people of rural population of a district of Uttar Pradesh, India. Int J Med Sci Pub Heal. 2014;3(9):1157-60.
46. Zhao M, Haley DR, Nolin JM, Dunning K, Wang J, Sun Q. Utilization, cost, payment, and patient satisfaction of rehabilitative services in Shandong, China. Heal Pol. 2009;93(1):21-6.

47. Zongjie $Y$, Hong $D$, Zhongxin $X$, Hui $X$. A research study into the requirements of disabled residents for rehabilitation services in Beijing. Disabil Rehabil. 2007:29(10):825-33.

48. Darzi AJ, Officer A, Abualghaib O, Akl EA. Stakeholders' perceptions of rehabilitation services for individuals living with disability: a survey study. Health Qual Life Outcomes. 2016;14(1):1.

\section{Publisher's Note}

Springer Nature remains neutral with regard to jurisdictional claims in published maps and institutional affiliations.
Ready to submit your research? Choose BMC and benefit from:

- fast, convenient online submission

- thorough peer review by experienced researchers in your field

- rapid publication on acceptance

- support for research data, including large and complex data types

- gold Open Access which fosters wider collaboration and increased citations

- maximum visibility for your research: over $100 \mathrm{M}$ website views per year

At BMC, research is always in progress.

Learn more biomedcentral.com/submissions 